\title{
Control Strategies and Daily Affect
}

\section{Couples Adapt to New Functional Limitations}

\author{
Nina Knoll ${ }^{1}$ (D), Jan Keller ${ }^{1}$, Aleksandra Luszczynska ${ }^{2,3}$, Urte Scholz ${ }^{4,5}$, \\ Christina Röcke ${ }^{5}$, Mark Schrader ${ }^{6}$, and Jutta Heckhausen ${ }^{7}$ \\ ${ }^{1}$ Department of Education and Psychology, Freie Universität Berlin, Germany \\ ${ }^{2}$ Faculty of Psychology, SWPS University of Social Sciences and Humanities, Wroclaw, Poland \\ ${ }^{3}$ Trauma, Health, \& Hazards Center, University of Colorado at Colorado Springs, Colorado Springs, USA \\ ${ }^{4}$ Department of Psychology, University of Zurich, Switzerland \\ ${ }^{5}$ University Research Priority Program (URPP) "Dynamics of Healthy Aging”, University of Zurich, Switzerland \\ ${ }^{6}$ Department of Urology, Helios Kliniken, Berlin, Germany \\ ${ }^{7}$ Department of Psychological Science, University of California, Irvine, CA, USA
}

\begin{abstract}
Adjusting strategies to manage daily goal pursuit with new functional limitations may impact not only the affect of patients, but also that of their partners. Associations between patients' control strategies and both partners' affect were examined at the onset of patients' incontinence following prostatectomy. Eight-day diary data from 180 heterosexual couples were used to fit two-level models. In patients, investing personal resources to keep up goal pursuit despite incontinence (selective primary control) was associated with better affect, particularly when incontinence was pronounced. Yet, partners' decreased negative affect coincided with patients' asking for help and using technical aids (compensatory primary control) when the incontinence was severe. Patients and partners may benefit from different control strategies used by patients, especially when their functional limitations are pronounced.
\end{abstract}

Keywords: radical prostatectomy, incontinence, control strategies, couples, affect

Patients with prostate cancer undergoing surgical removal of the prostate gland (i.e., radical prostatectomy; RP) face a number of challenges to their independence as they recover from the side effects of surgery (Chen et al., 2017; Knoll, Wiedemann, Schultze, Schrader, \& Heckhausen, 2014). Because functional limitations may fluctuate and change postsurgery, patients need to flexibly adjust their control striving for independence to whatever their current level of functioning is. A number of studies documented that patients' partners, who are usually also their primary informal caregivers, take great interest in all phases of their partners' disease, treatment, and recovery (Eton, Lepore, \& Helgeson, 2005; Gray, Fitch, Phillips, Labreque, \& Fergus, 2000). Partners also have to adapt to the patients' functional limitations and the way patients navigate difficulties when pursuing goals of daily living (Arrington, 2005; Knoll et al., 2015; Resendes \& McCorkle, 2006). In this study, we examined both patients' and their partners' experiences of the postsurgical functional limitations, the control strategies patients used to navigate these limitations, and their relations with patients' and partners' daily affect.

\section{RP and Postsurgery Functional Limitations}

Prostate cancer is now the second most common agingrelated cancer in men worldwide (Bray et al., 2018), with RP being a standard treatment (Heidenreich et al., 2014). Whereas mortality outcomes of RP were reported to be better than those of other standard treatment options (Wallis et al., 2016), postoperative functional limitations, including urinary incontinence and sexual dysfunctions, are highly frequent and limit patients' quality of life (Chen et al., 2017). Compared with sexual dysfunctions, incontinence seems to be a more consistent correlate of lowered quality of life in patients in the 2 years following RP (Rondorf-Klym \& Colling, 2003).

In most patients following RP, incontinence sets in and is most pronounced immediately following the removal of the indwelling postoperative catheter (Prabhu, Sivarajan, Taksler, Laze, \& Lepor, 2014). Although incontinence was shown to recede within 6 to 12 months in most patients, on an individual level its course is hard to predict; about $15 \%$ of patients report poor urinary control even at 
Table 1. Brief definitions of control strategies and control-strategy related hypotheses

\begin{tabular}{lll}
\hline Control strategy & \multicolumn{1}{c}{ Brief definition } & \multicolumn{1}{c}{ Related hypotheses } \\
\hline Selective primary control & $\begin{array}{l}\text { Investing personal resources (e.g., effort, time) into } \\
\text { goal pursuit, even if obstacles are encountered (i.e., } \\
\text { persistence) }\end{array}$ & $\begin{array}{l}\text { Patients' use of selective control strategies: Negative } \\
\text { associations with negative affect and positive } \\
\text { association with positive affect in patients (H3); } \\
\text { associations with partners' affect explored }\end{array}$ \\
$\begin{array}{lll}\text { Intensifying one's commitment to achieve a goal (e.g., } \\
\text { reminding oneself of the importance of the goal) }\end{array}$ & $\begin{array}{l}\text { Using detours or external resources (e.g., technical } \\
\text { aids, help) to achieve one's goals }\end{array}$ & $\begin{array}{l}\text { Patients' use of compensatory control strategies: } \\
\text { Compensatory primary control }\end{array}$ \\
$\begin{array}{ll}\text { Compengaging from goal and protecting motivational } \\
\text { resources for use in other goal pursuits }\end{array}$ & $\begin{array}{l}\text { positive associations with positive affect in patients } \\
\text { (H4) and partners (H5) }\end{array}$ \\
\hline
\end{tabular}

Note: H: Hypothesis. All hypotheses refer to within- and between-person associations.

24 months following RP (Chen et al., 2017). Initially, patients have little direct means of controlling incontinence, except for using sanitary pads and restricting daily activities to environments that provide restrooms (Ahnis \& Knoll, 2008).

\section{The Motivational Theory of Lifespan Development}

A model highly suitable to capture the process of individual adaptation to the onset of morbidity-related functional limitations is the motivational theory of lifespan development (MTD; e.g., Heckhausen \& Schulz, 1995, Heckhausen, Wrosch, \& Schulz, 2010, 2019). MTD proposes that control striving to reach important goals in life critically depends on the degree to which chosen goals are attainable. Strategies to control goal pursuit (see Table 1 for an overview) include those that address the environment (primary control strategies) and those that address internal processes such as goal-setting, motivational investment, and affective response to failure and loss (secondary control strategies; cf. Rothbaum, Weisz, \& Snyder, 1982). MTD conceptualizes the use of such control strategies at different levels of temporal resolution, including the pursuit of long-term developmental goals (e.g., family planning) in the face of developmental deadlines (e.g., menopause; Heckhausen et al., 2010, 2019) as well as the pursuit of short-term goals, such as the maintenance of activities of daily living while dealing with health-related functional limitations (Heckhausen, Wrosch, \& Schulz, 2013; Schilling et al., 2016; Schulz, Heckhausen, \& O’Brien, 2000; Wahl, Becker, Burnmedi, \& Schilling, 2004).

Primary control strategies are assumed to drive the motivational system and refer to attempts to change the external world to pursue one's goals. Heckhausen et al. (2010, 2019; Table 1) distinguish two primary control strategies: Selective primary control refers to investing personal resources, such as effort or time, into goal pursuit, even if barriers are encountered. For instance, when persons are facing functional limitations such as urinary incontinence, the maintenance of daily activities typically requires more preparation (order pads, plan restroom routes) and time (e.g., for packing protective measures or a change of clothes before leaving the house). If individuals are willing to invest this effort and time to keep up daily routines instead of refraining from outdoor activities as much as possible, they would practice selective primary control. Compensatory primary control is used when the capacity for goal pursuit is more severely limited or the goal is otherwise very difficult to attain. Here, detours (e.g., use routes with public restrooms) or external resources, such as technical aids (e.g., sanitary pads) or help from others, are actively used to achieve one's goals (Heckhausen et al., 2010, 2019).

Secondary control strategies target internal processes to regulate goal pursuit or disengage from it (Heckhausen et al., 2010, 2019; Table 1). Using selective secondary control, individuals intensify their commitment to achieve a goal, for example, by reminding themselves of how important a particular goal is to them or of how proud they will feel once they have accomplished that goal. If goal attainment is out of reach, however, disengaging from it may be the better choice. Compensatory secondary control entails goal disengagement and the protection of motivational resources for use in other goal pursuits. Heckhausen et al. (2019) point out that measures to protect one's motivational resources upon disengagement from a goal may take different forms, including dimensional comparison, when persons remind themselves that in other areas of life they are functioning quite well.

In a recent overview, Heckhausen and colleagues (2019) reviewed the different roles of emotions and affect during goal pursuit. For instance, when consequences of goal attainment are anticipated, emotions can function as incentives for, or instigators of action. Moreover, successful goal attainment can enhance positive or reduce negative affect, depending on the nature of the pursued goal. Likewise, when a goal cannot be attained and must be abandoned, 
negative affect arising from compromised self-esteem can be regulated by use of compensatory secondary control strategies that protect motivational resources (Heckhausen et al., 2019).

Concerning emotional consequences of goal pursuit, individuals' use of primary and secondary control were shown to be beneficial while navigating health-related barriers, especially when control strategies were used to pursue goals that are attainable in terms of opportunities for, and constraints to the individual's control striving (Heckhausen et al., 2010; 2019; Wrosch, Schulz, \& Heckhausen, 2004). In line with this, even goal disengagement, as part of compensatory secondary control, was shown to be associated with enhanced quality of life (Barlow et al., 2019), namely, when health problems were uncontrollable and therefore selective primary control striving would have been wasteful and frustrating (Hall, Chipperfield, Heckhausen, \& Perry, 2010; Schilling et al., 2016; Wrosch et al. 2004).

\section{Extending Predictions of the Motivational Theory of Lifespan Development to an Interpersonal Level}

To date, relatively much is known about how the use of control strategies is related to the emotional adaptation of goal pursuers to health issues (e.g., Heckhausen et al., 2019). A comparatively neglected field of study, however, is whether and how patients' use of control strategies in their daily goal pursuit is related to affective responses of close others, and whether the use of some control strategies may have more consistent interpersonal effects than others.

At the onset of functional limitations, selective control strategies that emphasize self-reliance are likely used by patients in attempts to reclaim their premorbidity level of functioning and independence in daily living. Patients invest available motivational resources (selective primary control) and where necessary enhance their own motivational commitment (selective secondary control) to particularly important goals to maintain their daily activities (cf. Phillips et al., 2000). From a partner's perspective, both processes may be somewhat less observable than those that entail changes in the couple's daily living, such as when patients give up certain activities. Consequently, partners' emotional responses to patients' use of selective control strategies might not be as consistent or pronounced. A notable exception may occur when, as a result of intense use of selective primary and secondary control, patients run the risk of overtaxing themselves and partners respond with worry (Phillips et al., 2000).
On the other hand, patients' adjustments to daily activities that are steered by compensatory control strategies should be more salient and easier to detect and may thus be expected to have more consistent interpersonal effects on partners. Using compensatory primary control, patients enlist help from their social network or take detours to pursue their goals, for instance, by using technical aids when functional capacity is limited. Both compensatory primary control strategies may affect patients' partners, either via direct requests for help or via challenges and benefits encountered with the use of technical aids when patients and partners pursue common goals. For example, findings from the social support literature in the context of couples' adaptation to patients' functional limitations following RP indicated that active requests for help from patients were predictably met with provision of the same by the partner (Knoll, Burkert, Roigas, \& Gralla, 2011; Resendes \& McCorkle, 2006). Also, implementing patients' use of technical aids following RP, such as finding the right pads or negotiating means of transportation for pads while pursuing out-of-home activities (Ahnis \& Knoll, 2008), was reported to be handled by the couple as a team (Gray et al., 2000; Phillips et al., 2000). Furthermore, in couples dealing with one partner's health-related functional challenges, support provision was repeatedly shown to be associated with better affect in the support provider (e.g., Belcher et al., 2011; Kroemeke, Knoll, \& Sobczyk-Kruszelnicka, 2019).

Patients' use of compensatory secondary control, that is, disengaging from goals and protecting their motivational resources, is also likely to affect their partners. On the one hand, the pursuit of goals of daily living by couple members is often shared or coordinated (Fitzsimons, Finkel, \& vanDellen, 2015; Hoppmann \& Gerstorf, 2014): If one partner disengages from pursuing a goal because of functional limitations, shared or coordinated goal pursuit must be renegotiated, which may impact both partners' affective responses, for instance, when healthy partners have to temporarily take on an additional load. On the other hand, violations of equity principles in couples were shown to be tolerated and indeed thought to be fairer by spouses appraising scenarios of couples where one partner faced severe cancer-related functional limitations (Kuijer, Buunk, \& Ybema, 2001). Moreover, soon after RP, partners have been reported to worry about patients' taking on too many activities instead of being easy on themselves (Phillips et al., 2000), which may indicate partners' appreciation of patients' goal disengagement at this time. Therefore, during early phases of adaptation to RP-related functional limitations, patients' use of compensatory secondary control may be beneficial for their (Wrosch et al., 2004; Barlow et al., 2019) and their partners' affective responses. 
In sum, it is expected that patients' use of compensatory control strategies in handling daily life with new functional limitations has positive effects on their partners' affective responses. Consistent effects of patients' use of selective control strategies, on the other hand, seem less likely and are explored.

\section{Aims and Hypotheses}

This study examines patients' and partners' adaptation to the onset of urinary incontinence in patients over the course of the first week following the removal of the indwelling postoperative catheter after RP. Patients' levels of incontinence and daily use of control strategies are investigated as predictors of the affect of both patients and partners as they initially adapt to the onset and unpredictable course of this functional limitation.

This study contributes new evidence on the immediate affective correlates of the post-RP experience of patients and their partners. It provides first evidence of individual daily use of control strategies of patients coming to terms with newly experienced health-related functional limitations, and it extends the investigation of affect correlates of control strategy use from an individual to an interpersonal level. Moreover, this study uses a diary design, which affords the opportunity to separate within-person from between-person associations of proposed predictors and outcomes in patients and partners. To date, predictions of the MTD have mostly been investigated from a betweenperson perspective (cf. Heckhausen et al., 2019), however, little is known about whether predictions hold for withinperson associations that capture flexible adaptation of control-strategy use and its associations with affect.

In accordance with evidence and propositions reviewed above, we hypothesize that the severity of incontinence experienced by patients following RP is associated with patients' (Hypothesis [H] 1) and partners' (H2) daily affect, that is, positive associations with negative affect and negative associations with positive affect are expected. It is also hypothesized that patients' use of selective primary and secondary control strategies is associated with higher positive affect and lower negative affect in patients (H3). Moreover, it is hypothesized that patients' use of compensatory primary and secondary control is associated with patients' (H4) and partners' (H5) daily affect. Specifically, it is expected that, during this early phase of adaptation to postsurgical incontinence, patients' use of compensatory control is associated with less negative affect and more positive affect in both patients and partners (Table 1). All hypotheses refer to both within-person and between-person associations.

In addition to these hypotheses, we explore the potential associations of patients' use of selective control strategies on their partners' daily affect, and whether any of the control strategy-affect associations are further moderated by indicators of patients' incontinence severity.

\section{Method}

\section{Procedure}

Data came from a larger longitudinal project with couples managing patients' postsurgical sequelae following RP (e.g., Knoll et al., 2014). This report includes data from the first measurement prior to patients' surgeries and from an 8-day daily diary phase that occurred after discharge from the hospital, starting on the day of the removal of their postsurgical indwelling catheters. Prior studies using data from this project focused on four additional longer-term follow-up assessments up to 7 months postsurgery (e.g., Knoll et al., 2014, 2015). Couples received a compensation of 110 EUR at the end the study for full study participation. The study procedure was approved by the Institutional Review Board of the university hospital where patients had been treated.

The couples were recruited from two Departments of Urology of a large German university hospital between 2009 and 2011. The first measurement took place upon patients' admission to the hospital, one day prior to surgery. Study research assistants approached the patients and their partners at the Departments of Urology, presented information on the study, explained study materials, and asked for written informed consent. Questionnaires were left with participants and picked up later on the same day. If partners were not present, their study materials were either left with the patients to hand to their partners later or sent to the couples' homes via mail. Postoperative 8-day diary assessments started on the day of catheter removal following patients' discharge from the hospital. Following catheter removal, the patients and their partners were approached by research assistants at the Departments of Urology and instructed how to complete the diaries. The patients and partners were asked to complete diaries each night before going to bed, to do so independent of each other, and to return completed diaries via mail. If the partners were not present, patients were handed the diary material and written instructions for their partners. Couples were called on the following day and asked whether they had any questions about completing the diaries.

\section{Participants}

A total of 209 patients scheduled for RP and their partners were enrolled in the study. Inclusion criteria were that patients were undergoing RP and living in a relationship 
with a heterosexual partner. Exclusion criteria were not having a partner, the partner's refusal to participate in the study, and/or insufficient comprehension of the German language. Of the 209 couples enrolled, 15 couples dropped out immediately following their inclusion in the study, and another 14 couples dropped out before the diary assessment (cumulative dropout at this point: $13.88 \%$ ). A total of 180 patients $(86.12 \%$ of 209$)$ and 177 partners $(84.69 \%$ of 209) returned diaries with at least one diary day completed. Returning any diary data (continuers: coded 1) was associated with patient reports on living with children in the household (less likely the case in continuers; $r h o=-.15$, $p=.048$ ) and partner multimorbidity (higher in continuers; $r h o=.23, p=.001)$.

Of the couples who returned any diary data, up to $2.78 \%$ of patients and up to $2.26 \%$ of partners chose not to relay sociodemographic information at the first measurement point. Patients' mean age was 63.43 years $(S D=6.73$, range $46-77)$, partners' mean age was 60.18 years $(S D=7.84$, range 39-75). Mean relationship duration as reported by patients was 32.40 years $(S D=13.96)$. Most patients were married to their partners $(87.60 \%)$, and the remainder were in a committed relationship. Most patients $(88.70 \%)$ and partners $(85.88 \%)$ reported having children. Regarding school education, $50.29 \%$ of patients and $40.36 \%$ of partners reported more than 10 years of schooling, the remainder reported 9 or 10 years of schooling. More than half of the patients (56.25\%) and $48.02 \%$ of the partners were retired. Patients' tumors varied in size (TNM classification; "T": 1 = $1.11 \% ; 2=66.11 \% ; 3=32.22 \%$ ), 17 tumors had spread to the lymph nodes ("N": $1=9.44 \%$ ), and one had metastasized (“M": $1=0.55 \%)$.

\section{Measures}

Except for the multimorbidity of patients and partners, all variables were assessed daily. To determine how well daily measures (of at least two items) were able to capture change (reliability of measurement of change; $\mathrm{R}_{\mathrm{C}}$ ) and stable between-person differences (reliability of the overall mean of item responses across days; $\mathrm{R}_{\mathrm{KF}}$, where $\mathrm{k}$ : number of days; f: fixed set of items), we used a method proposed by Cranford and colleagues (2006).

The daily positive and negative affect of patients and partners were assessed with a 10-item short form of the Positive and Negative Affect Schedule (PANAS; MacKinnon et al., 1999). Response scales ranged between 0 (not at all) and 3 (very much). Reliabilities for negative affect were $\mathrm{R}_{\mathrm{C}}=.77$ and $\mathrm{R}_{\mathrm{KF}}=.98$ in patients and $\mathrm{R}_{\mathrm{C}}=.71$ and $\mathrm{R}_{\mathrm{KF}}=.97$ in partners. Reliability indicators for positive affect were $\mathrm{R}_{\mathrm{C}}=.57$ and $\mathrm{R}_{\mathrm{KF}}=.98$ in patients and $\mathrm{R}_{\mathrm{C}}=.58$ and $\mathrm{R}_{\mathrm{KF}}=.97$ in partners.
Daily patient-reported urinary incontinence was measured by the German short form of the International Consultation of Incontinence Questionnaire (ICQ-SF; Karantanis, Fynes, Moore, \& Stanton, 2004). The ICQ-SF weighted sum score, consisting of three items assessing frequency of incontinence, amount of urine leaked, and burden by incontinence, ranges from 0 to 21 . $R_{C}$ was .57 , whereas $R_{K F}$ was 99. Partner-reports of patients' burden by incontinence, was assessed by the burden by incontinence item of the ICQ-SF [response scale: 0 (not at all) to 10 (strongly)], which was rephrased: "How strongly did your partner feel affected by leaking urine?" Partners were instructed to indicate strength of patients' burden on that day.

Patient-reported daily incontinence-specific control strategies were measured with an adapted short form of the Health-Specific Optimization in Primary and Secondary Control Scales (Schulz \& Heckhausen, 1998; for item wording, see Table S1 in Electronic Supplemental Material ESM 1). Response scales ranged from 1 (does not at all apply) to 5 (applies exactly). Reliability indicators for selective primary control were $\mathrm{R}_{\mathrm{C}}=.53$ and $\mathrm{R}_{\mathrm{KF}}=.98$; for selective secondary control they amounted to $\mathrm{R}_{\mathrm{C}}=.45$ and $\mathrm{R}_{\mathrm{KF}}=$ .98; and for compensatory primary control they were $\mathrm{R}_{\mathrm{C}}=$ .23 and $\mathrm{R}_{\mathrm{KF}}=.96$. All were assessed with two-item scales. Compensatory secondary control was assessed with four items, with $\mathrm{R}_{\mathrm{C}}=.48$ and $\mathrm{R}_{\mathrm{KF}}=.98$. In sum, all $\mathrm{R}_{\mathrm{C}}$ were low and lower than their respective $\mathrm{R}_{\mathrm{KF}}$ counterparts, probably because of the small number of items. This typically has a higher impact on $\mathrm{R}_{\mathrm{C}}$ than on $\mathrm{R}_{\mathrm{KF}}$ because of the aggregation across days in the latter (Cranford et al., 2006). Moreover, the $\mathrm{R}_{\mathrm{C}}$ indicator for compensatory primary control was particularly low, likely because the scale consisted of one item describing use of technical aids to accomplish daily activities and another the request of help from other persons. This subscale was thus framed more in a "multiple-act" manner (Carver, Scheier, \& Weintraub, 1989; p. 271) than the other control strategy subscales, which were framed in a more abstract, construct-oriented way. Whereas the former approach carries a higher risk of low internal consistency, examples from the coping literature show that this is not necessarily a risk for validity (e.g., Carver et al., 1989). Same-day between-person correlations among control strategies fluctuated over the course of the assessment week and were moderate to high in size. Consistently high correlations $(r=.62$ to $r=.72$, all $p s<.001)$ emerged between selective primary and selective secondary control.

Patient and partner multimorbidity was assessed at the first measurement point in time using a list of 34 chronic diseases (adapted from Charlson, Szatrowski, Peterson, \& Gold, 1994). Multimorbidity was captured with a sum score of present diseases assessed via self-report. 


\section{Data Analyses}

Patients and partners served different roles in this study, since only one member of the couple, the patient, experienced incontinence. As a result, except for daily affect, most data were not assessed fully dyadically. For instance, incontinence-specific control strategies were assessed from patients only, and incontinence indicators were assessed as self-reports from patients and in a reduced form as other-reports from partners. Therefore, and to limit model complexity, we fit separate models for patients and partners. However, because members of a couple tend to covary in their daily affect (e.g., Hoppmann \& Gerstorf, 2014), in the main analyses, a respective partner effect of the specific affect indicator that served as an outcome was accounted for as a covariate.

First-day diary data were excluded from the analysis as visual inspection indicated initial elevation in some variables (Shrout et al., 2018). Furthermore, $n=14$ patients returned to wearing an indwelling catheter during the diary week, with individual wear time varying between 1 and 6 days. All days when catheters were worn ( $n=45$ days from these 14 patients) were removed from the data as they did not reflect the experience of the population under study.

The data were analyzed using IBM SPSS 25 . For main analyses, two-level mixed models (level 1: within-person level; level 2: between-person level) predicting patient or partner affect indicators were fit. Following suggestions by Bolger and Laurenceau (2013), we first centered the mixed time-varying predictors and covariates of the models to arrive at meaningful interpretations of zeros, and to divide the within-parts from the between-parts of their variance. First, we subtracted the grand mean (across subjects and timepoints) from the predictors' and covariates' raw scores (i.e., grand-mean centering). Using these previously grandmean centered versions of predictors and covariates, we determined the individual person-means across time points [henceforth denoted by "(between)"] and the daily withinsubject deviations from these person means [henceforth denoted by "(within)"]. Additionally, linear and up to quadratic time trends were created as within-person level covariates and centered on the first diary day used in this study. Multimorbidity, assessed only at the first measurement point, was used as another between-person level covariate and was grand-mean centered.

To illustrate the two-level models that were then fit, let us use Model 1 (see Table 3) as an example. Patient daily negative affect served as an outcome. Predictors at the withinperson level were patient incontinence (within), patient selective primary control, selective secondary control, compensatory primary control, and compensatory secondary control (each within). Within-person level covariates were time and partner negative affect (within). Between-person level predictors were patient incontinence (between), patient selective primary control, selective secondary control, compensatory primary control, and compensatory secondary control (between). Between-person level covariates were patient multimorbidity (between) and partner negative affect (between). Note that the intercept of this model denotes the predicted value of daily patient negative affect when all predictors and covariates in the model are zero (e.g., average).

Models with partner affect as outcomes included respective within-level and between-level indicators of patient affect, partner-reported patient burden by incontinence, and patient control strategies in addition to time (withinperson level) and partner multimorbidity (between-person level) as other covariates. If interactions between predictors were tested, their respective within- and between-level versions were included in the models. Interactions were followed up with simple-slope analyses and then plotted (Preacher, Curran, \& Bauer, 2006). Only interactions that were found to be statistically significant in preliminary analyses are reported.

Testing random effects, priority for keeping it "maximal" (Barr, Levy, Scheepers, \& Tily, 2013, p. 255) was given to predictors involved in hypotheses (i.e., focal predictors). First, models estimating all random effects of focal predictors at once were fit, but none converged. Then a sequence of models was fit in which just one of the focal predictors was estimated as a random effect. If any of these models did not converge, their random effects were not further considered, whereas if the models converged, the findings regarding this focal predictor in fixed and random model versions were compared. If fixed-effect estimates for this focal predictor turned out to be nonsignificant once the random effect had been estimated, this random effect was kept. Then, all (remaining) possible combinations of random effects of focal predictors were tested, and the maximal version that still converged was retained. Thereafter, a sequence of additional models estimating random effects of the remaining covariates was tested. In models with interactions, a similar sequence of tests was performed, except that random effects of interaction terms were always given priority.

We used a restricted maximum likelihood estimation and an autoregressive error variance-covariance structure (AR1) (Bolger \& Laurenceau, 2013). Within- and betweenperson level findings of full models, accounting for covariates, incontinence, and all control strategies as competing predictors, are reported. Sensitivity analyses following up on unique predictors and reexamination thereof in reduced models without competing predictors or covariates are reported in ESM 1. 
Table 2. Descriptive statistics of central variables

\begin{tabular}{|c|c|c|c|c|c|c|c|c|c|}
\hline \multirow[b]{2}{*}{$\begin{array}{l}\text { Scale } \\
\text { (range) }\end{array}$} & \multirow[b]{2}{*}{ ICC } & \multicolumn{3}{|c|}{$\begin{array}{c}\text { Fixed effect estimates } \\
(S E)\end{array}$} & \multicolumn{5}{|c|}{$\begin{array}{c}\text { Random effect estimates } \\
(S E)\end{array}$} \\
\hline & & Intercept & TIME & $\mathrm{TIME}^{2}$ & Intercept & TIME & $\mathrm{TIME}^{2}$ & $\begin{array}{l}\text { Level-1 } \\
\text { Residual }\end{array}$ & AR1-rho \\
\hline Patient-reported incontinence $(0-21)$ & 0.831 & $\begin{array}{c}8.999 \\
(0.381)^{\star \star \star}\end{array}$ & $\begin{array}{c}-0.175 \\
(0.046) \star \star \star\end{array}$ & & $\begin{array}{c}23.553 \\
(2.761)^{\star \star \star}\end{array}$ & $\begin{array}{c}0.195 \\
(0.042)^{\star \star \star}\end{array}$ & & $\begin{array}{c}3.410 \\
(0.276)^{\star \star \star}\end{array}$ & $\begin{array}{c}0.211 \\
(0.062) * \star\end{array}$ \\
\hline $\begin{array}{l}\text { Partner-reported patient burden } \\
\text { by incontinence }(0-10)\end{array}$ & 0.875 & $\begin{array}{c}4.990 \\
(0.264)^{\star \star \star}\end{array}$ & $\begin{array}{l}-0.071 \\
(0.029)^{\star}\end{array}$ & & $\begin{array}{c}11.172 \\
(1.318)^{\star \star \star}\end{array}$ & $\begin{array}{c}0.074 \\
(0.017)^{\star \star \star}\end{array}$ & & $\begin{array}{c}1.424 \\
(0.122)^{\star \star \star}\end{array}$ & $\begin{array}{c}0.272 \\
(0.060)^{\star \star \star}\end{array}$ \\
\hline Patients' negative affect $(0-3)$ & 0.584 & $\begin{array}{c}0.479 \\
(0.042)^{\star \star \star}\end{array}$ & $\begin{array}{l}-0.014 \\
(0.007)^{\dagger}\end{array}$ & & $\begin{array}{c}0.235 \\
(0.034)^{\star * *}\end{array}$ & $\begin{array}{c}0.004 \\
(0.001)^{\star \star}\end{array}$ & & $\begin{array}{c}0.128 \\
(0.008)^{\star \star \star}\end{array}$ & $\begin{array}{c}0.090 \\
(0.051)^{\dagger}\end{array}$ \\
\hline Patients' positive affect $(0-3)$ & 0.735 & $\begin{array}{c}1.371 \\
(0.050)^{\star \star \star}\end{array}$ & $\begin{array}{l}-0.0686 \\
(0.019)^{\star \star}\end{array}$ & $\begin{array}{c}0.010 \\
(0.003)^{\star \star}\end{array}$ & $\begin{array}{c}0.363 \\
(0.048)^{\star \star \star}\end{array}$ & $\begin{array}{c}0.016 \\
(0.008)^{\dagger}\end{array}$ & $\begin{array}{l}0.001 \\
(0.001)\end{array}$ & $\begin{array}{c}0.096 \\
(0.008)^{\star \star \star}\end{array}$ & $\begin{array}{c}0.068 \\
(0.062)\end{array}$ \\
\hline Partners' negative affect $(0-3)$ & 0.594 & $\begin{array}{c}0.524 \\
(0.037)^{\star \star \star}\end{array}$ & $\begin{array}{l}-0.020 \\
(0.007)^{\star \star}\end{array}$ & & $\begin{array}{c}0.178 \\
(0.027)^{\star \star \star}\end{array}$ & $\begin{array}{c}0.003 \\
(0.001)^{\star \star}\end{array}$ & & $\begin{array}{c}0.106 \\
(0.007)^{\star \star \star}\end{array}$ & $\begin{array}{c}0.109 \\
(0.057)^{\dagger}\end{array}$ \\
\hline Partners' positive affect $(0-3)$ & 0.694 & $\begin{array}{c}1.311 \\
(0.047)^{\star \star \star}\end{array}$ & $\begin{array}{l}-0.022 \\
(0.008)^{\star \star}\end{array}$ & & $\begin{array}{c}0.313 \\
(0.042) \star \star \star\end{array}$ & $\begin{array}{c}0.005 \\
(0.001)^{\star \star \star}\end{array}$ & & $\begin{array}{c}0.115 \\
(0.008)^{\star \star \star}\end{array}$ & $\begin{array}{c}0.110 \\
(0.056)^{\dagger}\end{array}$ \\
\hline $\begin{array}{l}\text { Patients' selective primary } \\
\text { control }(1-5)\end{array}$ & 0.771 & $\begin{array}{c}4.047 \\
(0.070) * \star \star\end{array}$ & $\begin{array}{c}0.001 \\
(0.010)\end{array}$ & & $\begin{array}{c}0.678 \\
(0.102)^{\star \star \star}\end{array}$ & $\begin{array}{c}0.005 \\
(0.003)\end{array}$ & & $\begin{array}{c}0.255 \\
(0.030)^{\star \star \star}\end{array}$ & $\begin{array}{c}0.371 \\
(0.068)^{* * \star}\end{array}$ \\
\hline $\begin{array}{l}\text { Patients' selective secondary } \\
\text { control (1-5) }\end{array}$ & 0.807 & $\begin{array}{l}3.837 \\
(0.080) * \star \star\end{array}$ & $\begin{array}{l}-0.013 \\
(0.011)\end{array}$ & & $\begin{array}{c}0.942 \\
(0.126) \star \star \star\end{array}$ & $\begin{array}{c}0.008 \\
(0.003)^{\star}\end{array}$ & & $\begin{array}{c}0.241 \\
(0.026)^{\star \star \star}\end{array}$ & $\begin{array}{c}0.346 \\
(0.066)^{* \star *}\end{array}$ \\
\hline $\begin{array}{l}\text { Patients' compensatory primary } \\
\text { control }(1-5)\end{array}$ & 0.762 & $\begin{array}{c}4.271 \\
(0.061)^{\star \star \star}\end{array}$ & $\begin{array}{c}-0.025 \\
(0.010)^{\star \star}\end{array}$ & & $\begin{array}{c}0.521 \\
(0.076) \star \star \star\end{array}$ & $\begin{array}{c}0.006 \\
(0.002)^{\star \star}\end{array}$ & & $\begin{array}{c}0.185 \\
(0.020) * \star \star\end{array}$ & $\begin{array}{c}0.361 \\
(0.066)^{\star \star \star}\end{array}$ \\
\hline $\begin{array}{l}\text { Patients' compensatory secondary } \\
\text { control (1-5) }\end{array}$ & 0.824 & $\begin{array}{c}3.345 \\
(0.069) \star \star \star\end{array}$ & $\begin{array}{l}-0.012 \\
(0.010)\end{array}$ & & $\begin{array}{c}0.738 \\
(0.091)^{\star \star \star}\end{array}$ & $\begin{array}{c}0.011 \\
(0.002)^{\star \star \star}\end{array}$ & & $\begin{array}{c}0.144 \\
(0.012)^{\star \star \star}\end{array}$ & $\begin{array}{c}0.229 \\
(0.063)^{\star \star \star}\end{array}$ \\
\hline
\end{tabular}

\section{Results}

\section{Descriptive Results}

Table 2 reports the descriptive results from two-level models estimating change in patients' and partners' central variables. Patient-reported incontinence, present to some degree in about $95 \%$ of patients, showed much betweenperson variability in terms of both starting points and slopes. On average, patient-reported incontinence severity fell just below the theoretical midpoint of the scale (at 8.99, the scale ranging between 0 and 21) at the beginning of the diary week and linearly decreased by about 0.18 points per day. Patients' reports on incontinence were mirrored by their partners' reports on patients' burden by incontinence. Partners' reports indicated a linear decrease in patients' burden by incontinence over time, with substantial between-person variation in starting points and slopes. Correlations of patient accounts of their own incontinence and partners' accounts of patients' burden by incontinence were $r_{\text {within }}=.26$ and $r_{\text {between }}=.75$ (all $p<.001$ ).

During the week, patients' (at $p=.051$ ) and partners' negative affect decreased linearly on average, albeit again with much between-person variance in intercepts and slopes. Whereas partners' positive affect decreased over time, patients' positive affect initially decreased on average but took an upward slope thereafter. Again, patients and partners varied significantly in terms of initial levels of positive affect. Rates of change varied for partners but not for patients.

Except for compensatory primary control, which decreased linearly, patients' use of most control strategies did not show systematic change. Significant betweenperson variation in both starting points and slopes was observed in most control strategies, except for selective primary control where no significant variation in slopes was observed (Table 2).

\section{Associations of Patients' Incontinence and Control Strategies with Patients' Daily Affect}

Estimates for the two-level models are reported in Table 3. Controlling for time, respective indicators of concurrent partner-affect, and patient multimorbidity, associations between proposed between- and within-person versions of predictors and patient negative (Model 1) and positive (Model 2) affect were estimated. Model 3, predicting patient negative affect, additionally examined an interaction of patient selective primary control and patient incontinence. Preliminary analyses indicated that no such statistically significant interactions emerged in models predicting patient positive affect. Thus, these models are not reported. 
Table 3. Patients' two-level model estimates with negative and positive affect as outcomes

\begin{tabular}{|c|c|c|c|c|c|c|}
\hline & \multicolumn{2}{|c|}{$\begin{array}{c}\text { Patients' negative affect } \\
\text { (Model 1) } \\
\end{array}$} & \multicolumn{2}{|c|}{$\begin{array}{c}\text { Patients' positive affect } \\
\text { (Model 2) } \\
\end{array}$} & \multicolumn{2}{|c|}{$\begin{array}{l}\text { Patients' negative affect } \\
\text { (Model 3) }\end{array}$} \\
\hline & Est (SE) & $p$ & Est (SE) & $p$ & Est (SE) & $p$ \\
\hline Intercept & $0.442(0.037)$ & $<.001$ & $1.382(0.043)$ & $<.001$ & $0.425(0.034)$ & $<.001$ \\
\hline Partner affect (between) & $0.340(0.069)$ & $<.001$ & $0.189(0.069)$ & .007 & $0.317(0.068)$ & $<.001$ \\
\hline Patient multimorbidity & $0.031(0.011)$ & .006 & $0.005(0.014)$ & .714 & $0.031(0.011)$ & .005 \\
\hline Patient incontinence (between) & $0.024(0.007)$ & .002 & $-0.047(0.010)$ & $<.001$ & $0.022(0.007)$ & .003 \\
\hline Patient selective primary control (between) & $-0.186(0.052)$ & $<.001$ & $0.111(0.066)$ & .095 & $-0.188(0.051)$ & $<.001$ \\
\hline Patient selective secondary control (between) & $0.074(0.049)$ & .133 & $0.135(0.063)$ & .034 & $0.054(0.049)$ & .269 \\
\hline Patient compensatory primary control (between) & $-0.002(0.052)$ & .964 & $0.010(0.066)$ & .877 & $-0.024(0.052)$ & .643 \\
\hline Patient compensatory secondary control (between) & $0.023(0.045)$ & .610 & $-0.048(0.058)$ & .407 & $0.018(0.044)$ & .682 \\
\hline $\begin{array}{l}\text { Patient selective primary control (between) } \times \\
\text { patient incontinence (between) }\end{array}$ & - & & - & & $-0.015(0.006)$ & .012 \\
\hline Time & $-0.004(0.007)$ & .565 & $-0.071(0.019)$ & $<.001$ & $-0.005(0.006)$ & .410 \\
\hline Time $^{2}$ & - & & $0.010(0.003)$ & .001 & - & \\
\hline Partner affect (within) & $0.214(0.042)$ & $<.001$ & $0.104(0.029)$ & $<.001$ & $0.183(0.031)$ & $<.001$ \\
\hline Patient incontinence (within) & $0.050(0.006)$ & $<.001$ & $-0.033(0.007)$ & $<.001$ & $0.043(0.008)$ & $<.001$ \\
\hline Patient selective primary control (within) & $-0.090(0.029)$ & .002 & $0.074(0.031)$ & .018 & $-0.068(0.036)$ & .061 \\
\hline Patient selective secondary control (within) & $-0.039(0.027)$ & .154 & $0.010(0.027)$ & .711 & $-0.046(0.033)$ & .168 \\
\hline Patient compensatory primary control (within) & $0.013(0.033)$ & .697 & $0.031(0.028)$ & .263 & $0.014(0.029)$ & .627 \\
\hline Patient compensatory secondary control (within) & $-0.040(0.040)$ & .331 & $0.054(0.034)$ & .119 & $-0.051(0.030)$ & .094 \\
\hline $\begin{array}{l}\text { Patient selective primary control (within) } \times \\
\text { incontinence (within) }\end{array}$ & - & & - & & $-0.055(0.023)$ & .021 \\
\hline \multicolumn{7}{|l|}{ Random effects } \\
\hline Intercept & $0.157(0.025)$ & $<.001$ & $0.193(0.025)$ & $<.001$ & $0.114(0.015)$ & $<.001$ \\
\hline Time & $0.002(0.001)$ & .009 & - & & - & \\
\hline Partner affect (within) & $0.047(0.023)$ & .044 & - & & - & \\
\hline Patient incontinence (within) & - & & $0.002(0.001)$ & .009 & $0.002(0.001)$ & .001 \\
\hline Patient selective primary control (within) & - & & $0.017(0.012)$ & .144 & $0.043(0.020)$ & .029 \\
\hline Patient selective secondary control (within) & - & & - & & $0.040(0.017)$ & .015 \\
\hline Patient compensatory primary control (within) & $0.017(0.015)$ & .265 & - & & - & \\
\hline Patient compensatory secondary control (within) & $0.054(0.023)$ & .019 & $0.021(0.015)$ & .159 & - & \\
\hline $\begin{array}{l}\text { Patient selective primary control (within) } \times \\
\text { incontinence (within) }\end{array}$ & - & & - & & $0.017(0.007)$ & .010 \\
\hline Residual & $0.093(0.007)$ & $<.001$ & $0.099(0.007)$ & $<.001$ & $0.085(0.006)$ & $<.001$ \\
\hline AR1-Rho & $0.091(0.057)$ & .112 & $0.226(0.052)$ & $<.001$ & $0.147(0.054)$ & .006 \\
\hline
\end{tabular}

Note: $n=168$. Patients: $1067 \leq n_{\text {observations }} \leq 1069$. Coefficients are unstandardized. Est: Estimate. SE: Standard error. Fixed effects "-": fixed effect was not part of the model. Random effects "-": Random effect was either not part of the model or model did not converge upon inclusion.

At the within-person level, and in accordance with $\mathrm{H} 1$, patient incontinence was associated with both affect indicators (Table 3). On days with more severe incontinence, patients reported more negative and less positive affect. In support of $\mathrm{H} 3$, on days with higher use of selective primary control, i.e., when patients invested many resources and much energy in pursuing their goals despite their incontinence, they also reported less negative and more positive affect (Table 3, Models 1 and 2). For patients' negative affect, this within-association was further qualified by patient incontinence (Table 3, Model 3). On days when patients used much selective primary control, they also reported lower negative affect, but only when they also experienced higher $(M+1 S D)$ levels of incontinence that day, simple slope $(S E)=-0.172$ (0.059), $z=-2.926, p=$ .003. At lower levels of daily incontinence $(M-1 S D)$, no within-person association of patients' use of selective primary control with negative affect emerged, simple slope $(S E)=0.035$ (0.054), $z=0.644, p=.519$ (Figure 1, Panel A). Not supporting $\mathrm{H} 3$ or $\mathrm{H} 4$, neither patient selective secondary control, indicating enhanced commitment to goal pursuit, nor any of the compensatory control strategies were related with any indicator of affect at the within-person level (Table 3). 
[Panel A: Patients, within-person level]

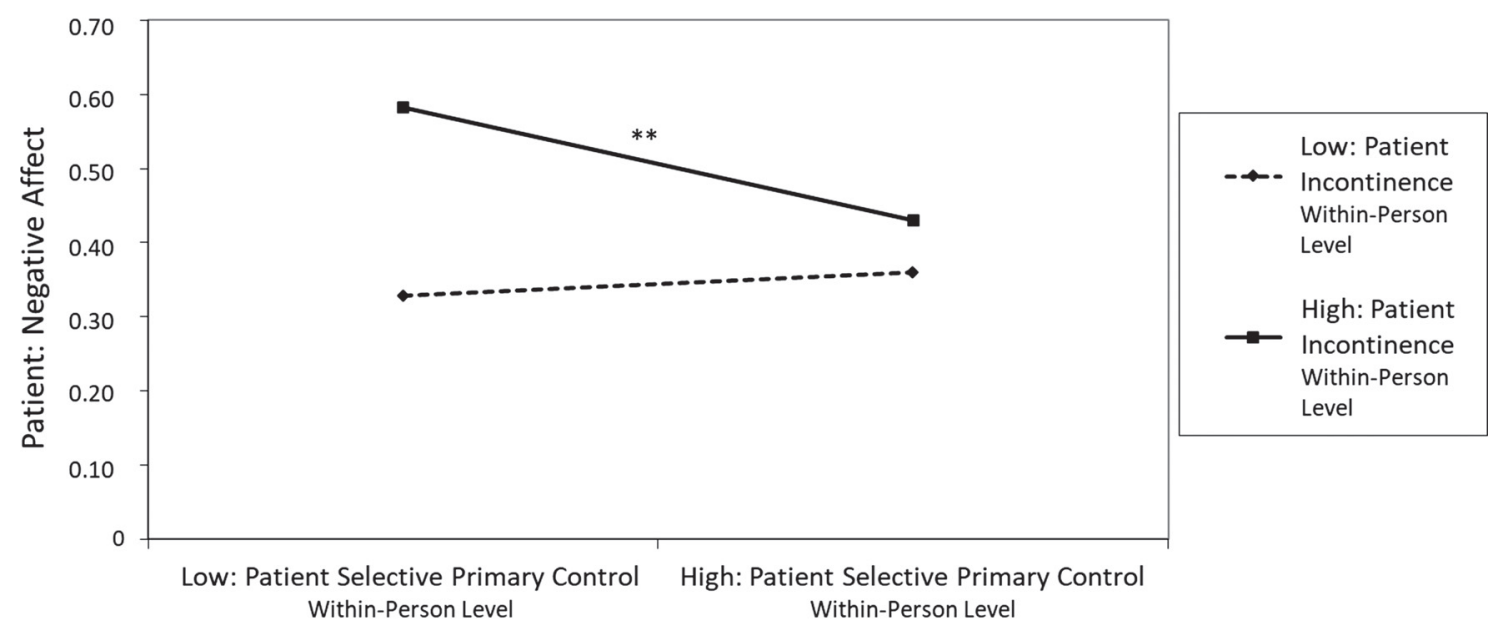

[Panel B: Patients, between-person level]

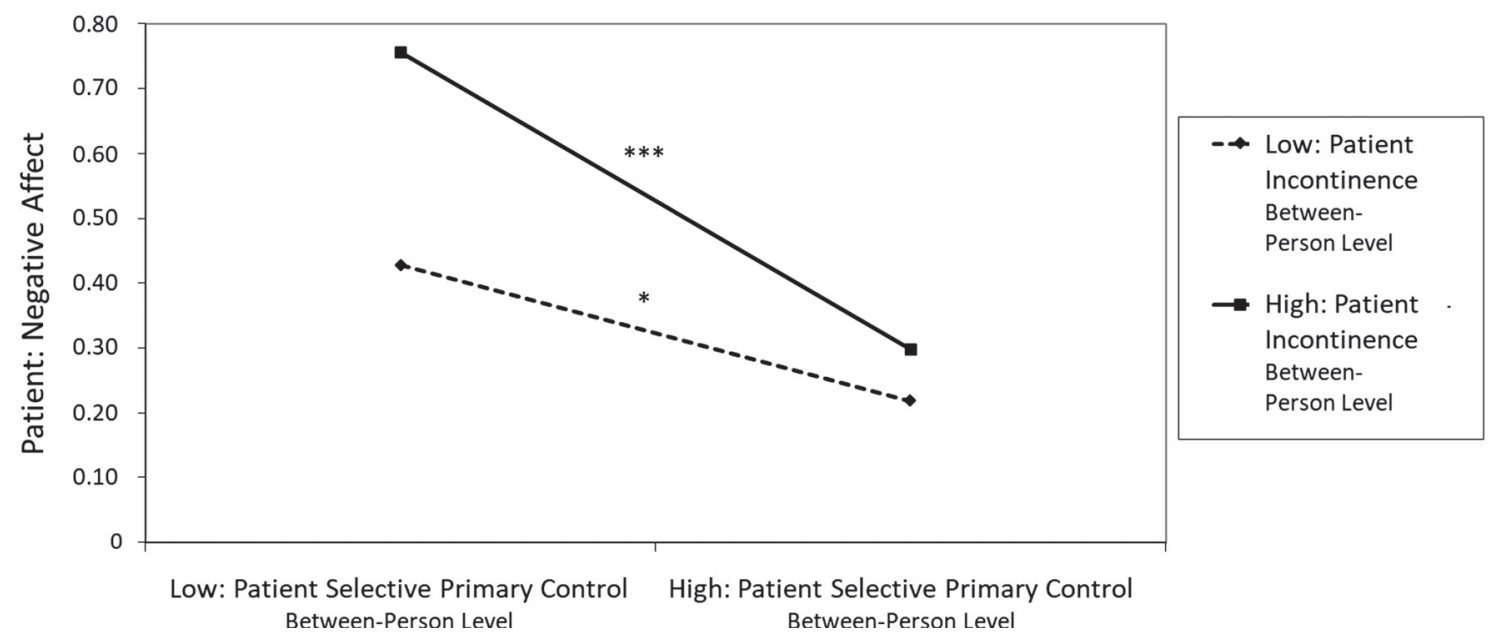

Figure 1. Plotted interaction terms for patients' negative affect. Patient-reported selective primary control $\times$ patient-reported urinary incontinence (within-person level) predicting patient negative affect (Panel A). Patient-reported selective primary control $\times$ patient-reported urinary incontinence (between-person level) predicting patient negative affect (Panel B). "High" and "Low" values plotted at $M \pm 1$ SD. ${ }^{*}<.05$; ${ }^{* *} p<.01 ; * * * p<.001$.

Between-person level findings were similar to those at the within-person level. In accordance with $\mathrm{H} 1$, average incontinence severity during the diary week was positively related with negative and negatively related with positive affect in patients. In partial support of $\mathrm{H} 3$, patients who, on average, used much selective primary control during the diary week, that is, invested many resources into goal pursuit, reported lower negative affect (Table 3, Model 1) than patients reporting lower use of selective primary control. Also resembling within-person level findings, the latter association was moderated by patients' mean incontinence severity during the week (Table 3, Model 3). At the between person-level, however, both patients with high [simple slope $(S E)=-0.258$ (0.060), $z=-4.331, p<.001]$ and low incontinence severity [simple slope $(S E)=-0.118$ (0.057), $z=-2.077, p=.038]$ reported lower negative affect when they used much selective primary control (Figure 1, Panel B). Slopes were more pronounced in patients with high average incontinence severity. Additionally, and also in partial accordance with $\mathrm{H} 3$, patients who used much selective secondary control, that is, reported high intensities of motivational commitment to achieve a goal on average, experienced higher positive, but not lower negative affect (Table 3, Model 2). Again, resembling findings at the within-person level, no support was found for $\mathrm{H} 4$. Neither patients' average use of compensatory primary, nor compensatory secondary control were associated with patient affect. 
Table 4. Partners' two-level model estimates with partners' negative and positive affect as outcomes

\begin{tabular}{|c|c|c|c|c|c|c|}
\hline & \multicolumn{2}{|c|}{$\begin{array}{c}\text { Partners' negative affect } \\
\text { (Model P1) } \\
\end{array}$} & \multicolumn{2}{|c|}{$\begin{array}{c}\text { Partners' positive affect } \\
\text { (Model P2) } \\
\end{array}$} & \multicolumn{2}{|c|}{$\begin{array}{c}\text { Partners' negative affect } \\
\text { (Model P3) }\end{array}$} \\
\hline & Est (SE) & $p$ & Est (SE) & $p$ & Est (SE) & $p$ \\
\hline Intercept & $0.494(0.033)$ & $<.001$ & $1.330(0.044)$ & $<.001$ & $0.510(0.034)$ & $<.001$ \\
\hline Patient affect (between) & $0.292(0.067)$ & $<.001$ & $0.293(0.082)$ & $<.001$ & $0.284(0.070)$ & $<.001$ \\
\hline Partner multimorbidity & $0.031(0.011)$ & .005 & $-0.016(0.016)$ & .312 & $0.031(0.011)$ & .006 \\
\hline Partner-report patient incontinence (between) & $0.029(0.009)$ & .002 & $-0.037(0.014)$ & .007 & $0.031(0.010)$ & .001 \\
\hline Patient selective primary control (between) & $-0.028(0.051)$ & .575 & $-0.107(0.070)$ & .126 & $-0.042(0.053)$ & .434 \\
\hline Patient selective secondary control (between) & $-0.014(0.047)$ & .769 & $0.075(0.068)$ & .270 & $-0.009(0.048)$ & .853 \\
\hline Patient compensatory primary control (between) & $-0.046(0.047)$ & .335 & $-0.033(0.068)$ & .635 & $-0.068(0.052)$ & .191 \\
\hline Patient compensatory secondary control (between) & $-0.001(0.044)$ & .981 & $0.027(0.064)$ & .680 & $0.002(0.046)$ & .959 \\
\hline $\begin{array}{l}\text { Patient compensatory primary control (between) } \times \\
\text { Partner-report patient incontinence (between) }\end{array}$ & - & & - & & $-0.012(0.012)$ & .317 \\
\hline Time & $-0.016(0.006)$ & .012 & $-0.021(0.008)$ & .006 & $-0.018(0.007)$ & .006 \\
\hline Patient affect (within) & $0.190(0.031)$ & $<.001$ & $0.149(0.036)$ & $<.001$ & $0.169(0.031)$ & $<.001$ \\
\hline Partner-report patient incontinence (within) & $0.034(0.011)$ & .004 & $-0.028(0.011)$ & .019 & $0.021(0.009)$ & .022 \\
\hline Patient selective primary control (within) & $0.019(0.027)$ & .471 & $0.001(0.030)$ & .968 & $0.009(0.027)$ & .735 \\
\hline Patient selective secondary control (within) & $0.009(0.027)$ & .733 & $0.049(0.029)$ & .094 & $-0.004(0.027)$ & .873 \\
\hline Patient compensatory primary control (within) & $-0.052(0.028)$ & .064 & $-0.005(0.031)$ & .862 & $-0.045(0.029)$ & .125 \\
\hline Patient compensatory secondary control (within) & $-0.005(0.030)$ & .870 & $0.003(0.033)$ & .924 & $-0.012(0.033)$ & .714 \\
\hline $\begin{array}{l}\text { Patient compensatory primary control (within) } \times \\
\text { Partner-report patient incontinence (within) }\end{array}$ & - & & - & & $-0.082(0.035)$ & .026 \\
\hline \multicolumn{7}{|l|}{ Random effects } \\
\hline Intercept & $0.121(0.021)$ & $<.001$ & $0.256(0.038)$ & $<.001$ & $0.131(0.023)$ & $<.001$ \\
\hline Time & $0.002(0.0009)$ & .014 & $0.004(0.001)$ & .002 & $0.003(0.001)$ & .004 \\
\hline Partner-report patient incontinence (within) & $0.003(0.002)$ & .133 & $0.002(0.002)$ & .385 & - & \\
\hline Patient selective primary control (within) & - & & $0.007(0.009)$ & .474 & - & \\
\hline Patient selective secondary control (within) & $0.002(0.007)$ & .727 & - & & - & \\
\hline Patient compensatory secondary control (within) & - & & - & & $0.013(0.011)$ & .237 \\
\hline $\begin{array}{l}\text { Patient compensatory primary control (within) } \times \\
\text { Partner-report patient incontinence (within) }\end{array}$ & - & & - & & $0.019(0.013)$ & .143 \\
\hline Residual & $0.096(0.006)$ & $<.001$ & $0.111(0.009)$ & $<.001$ & $0.094(0.007)$ & $<.001$ \\
\hline AR1-Rho & $0.069(0.058)$ & .237 & $0.140(0.064)$ & .028 & $0.083(0.058)$ & .152 \\
\hline
\end{tabular}

Note: Partners $n=171$. Partners: $1078 \leq n_{\text {observations }} \leq 1080$ because of missing values. Coefficients are unstandardized. Est: Estimate. SE: Standard error. Fixed effects "-": fixed effect was not part of the model. Random effects "-": Random effect was either not part of the model or model did not converge upon inclusion.

Sensitivity analyses using control strategies as single, not competing, predictors and without covariates yielded the same pattern of findings (see ESM 1, Table S2).

\section{Associations of Partner-Reported Patient Incontinence Burden and Patient Control Strategies with Partners' Daily Affect}

Estimates for two-level models are reported in Table 4 . Controlling for time, respective indicators of concurrent patient affect, and partner multimorbidity, partner $(\mathrm{P})$ models estimated associations of between- and withinperson versions of predictors and partners' daily negative (Model P1) and positive (Model P2) affect. Model P3, predicting partners' negative affect, additionally included an interaction of patient compensatory primary control with partner-reported patient burden by incontinence. As preliminary analyses indicated that no such statistically significant interactions emerged in models predicting partners' positive affect, these models are not reported.

At the within-person level, supporting $\mathrm{H} 2$, partner-reports of patient burden by incontinence were associated with partner negative and positive affect (Table 4). On days when partners rated patients' burden by incontinence as particularly high, partners experienced higher negative and lower positive affect. Not in support of H5, no statistically significant associations of within-person indicators of patient compensatory primary or secondary control with partners' affect emerged (Table 4, Models P1 and P2). However, a significant interaction term of patient compensatory primary control and partner-reported patient burden 


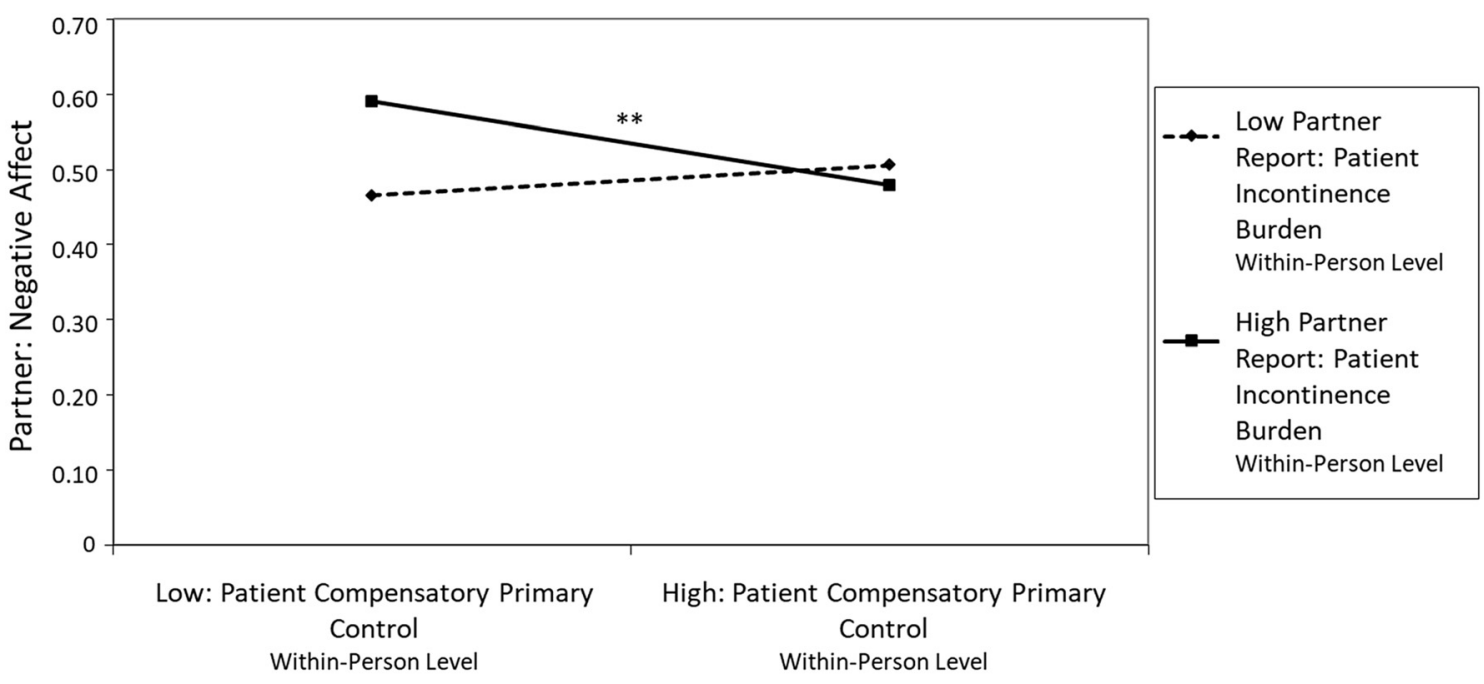

Figure 2. Plotted interaction term for partners' negative affect. Patient-reported compensatory primary control $\times$ partner-reported patient burden with urinary incontinence (within-person level) predicting partner negative affect. "High" and "Low" values plotted at $M \pm 1 S D$. **p<.01.

by incontinence emerged at the within-person level when partners' negative affect served as an outcome (Table 4, Model P3). The plotted interaction (Figure 2) indicates that, on days when partners rated patients' burden by incontinence as particularly high $(M+1 S D)$, patients' use of compensatory primary control, i.e., using technical aids and help to achieve goals of daily living, was associated with lower negative affect in partners [simple slope $(S E)=-0.141$ (0.050), $z=-2.823, p=.005]$. On days with lower partnerreported patient burden by incontinence $(M-1 S D)$, patients' use of compensatory primary control and partners' negative affect were unrelated [simple slope $(S E)=0.051$ (0.051), $z=1.002, p=.316]$. Moreover, none of patients' within-person indicators of selective control strategies were related with partners' daily affect.

Confirming $\mathrm{H} 2$ at the between-person level, average partner-reported patient incontinence burden was positively related with partners' negative affect and negatively related with their positive affect (Table 4). No simple nor moderated associations between patients' average use of any control strategy and partners' affect were observed at the between-person level. Thus, no support for H5 was encountered at this level of analysis.

Sensitivity analyses without covariates or competing predictors yielded the same pattern of findings (see ESM 1, Table S3).

\section{Discussion}

This study addressed prostate cancer patients' and their partners' adaptation to the onset of patients' urinary incontinence over 1 week following patients' RP. Patients' levels of incontinence and daily use of control strategies were investigated as correlates of patients' and partners' positive and negative affect.

As predicted (H1, $\mathrm{H} 2)$, both patients' and partners' affect was associated with the intensity of incontinence experienced by patients, at both levels of analysis and even while the concurrent affect of the respective other member of the couple was controlled. These findings of patients' and partners' higher negative affect and lower positive affect contingent on patients' incontinence episodes show the severity of day-to-day challenges faced by couples in coming to terms with the onset of this functional limitation. Previous qualitative studies reported converging patterns of patients' feelings of shame as well as patients' and partners' initial surprise about the impact of this functional limitation along with the initial hassle of finding the right technical aids and incorporating their use in daily life (Gray et al., 2000; Phillips et al., 2000).

In the present research, however, evidence for a beginning emotional adaptation in patients and partners also emerged early after surgery. Both patients' (at $p=.051$ ) and partners' negative affect decreased during the diary week. Moreover, after an initial downturn, patients' positive affect increased again. Decreasing levels of positive affect in partners over the diary week might reflect beginning signs of tiredness or less activation because of the caregiving load. Positive affect as operationalized in this study capitalized on high activation positive affect states such as being excited, alert, or enthusiastic (MacKinnon et al., 1999).

\section{Associations Between Patients' Control Strategies and Affect}

For patients, the findings partially supported predictions from MTD (e.g., Heckhausen et al., 2010) and H3 about 
relations between patients' use of selective control strategies to navigate goal pursuit despite incontinence.

Consistent with MTD's proposal that "primary control holds functional primacy in the motivational system" (Heckhausen et al., 2010, p. 32), selective primary control or the investment of personal resources into goal pursuit despite losses in functional health was a consistent withinand between-person correlate of more positive and less negative daily affect in patients. Notably, in terms of negative affect, selective primary control appeared to be particularly helpful for patients with pronounced incontinence severity. Both at the within- and the between-person levels, patients experiencing high levels of incontinence exhibited a stronger negative association between selective primary control and negative affect than patients with comparatively less pronounced incontinence. At higher levels of incontinence, an early sense of mastery in coping with this new functional limitation might have buffered patients' stress, even at the expense of having to invest more effort (e.g., Bandura, 1997). Moreover, reduced distress in these instances might indicate relief at being able to reclaim presurgery levels of functioning (Phillips et al., 2000). On the other hand, when incontinence was not pronounced, patients probably experienced less disruptions in their daily lives, thus running less risk to experience elevated negative affect.

Patients' use of selective secondary control, that is, boosting one's motivational commitment to a goal, was related with higher positive affect only at the between-level of analysis and not at all with patients' negative affect. Selective secondary control only needs to be used if goal commitment is threatened, which can be associated with worse affect. On the other hand, actively working against loss of goal commitment by using selective secondary control can improve affect. Maybe these two processes mostly cancelled each other out.

A similar explanation, combined with this study's focus on an early stage of patients' rehabilitation, might account for the overall lack of support for H4. No associations emerged between patients' compensatory control and their affect. As for compensatory primary control, seeking help and using technical aids, aside from being conductive of goal attainment if functional limitations are present, may also incur costs. For instance, until routines for use of sanitary pads are established, use of such technical aids might provoke irritation. Also, asking others for help can incur costs, such as feeling indebted (Kuijer et al., 2001) or embarrassed about the reason for having to seek help (Phillips et al., 2000). Both sorts of costs may have cancelled out elation or relief about goal attainment at this early stage of managing incontinence.

An unexpected lack of associations of compensatory secondary control, referring to goal disengagement and the protection of motivational resources, with patients' affect indicators might also be because of the early rehabilitation phase. First, if patients were aware that incontinence is likely to improve, they may not have expected lasting, but rather temporal goal disengagement at that time (Knoll et al., 2014). Also, during this time, patients and their partners were reported to be immersed in setting up routines to handle technical aids to curb the effects of incontinence (Phillips et al., 2000). Until such routines were set up, patients may have temporarily shelved goals that they expected to take up soon again, once they had mastered use of technical aids.

Another reason for not encountering within-person associations of compensatory control strategies with patient affect might be the low reliability of the measurement of change in these scales, which is discussed in the limitations section below.

\section{Associations Between Patients' Control Strategies and Partners' Affect}

The relationships between patient control strategy use and partners' affect differed from the relationships between patients' strategies and their own affect. In partial support of H5, compensatory primary control as practiced by patients was negatively related with their partners' negative affect - but only on days when partners thought patientburden by incontinence was pronounced. Patients' using technical aids and asking for help to curb particularly disruptive effects of incontinence episodes during daily goal pursuit could have relieved their partners for a number of reasons. First, using pads as technical aids when incontinence was very pronounced would have increased the couples' range of pursuit of common goals at least to some degree (Hoppmann \& Gerstorf, 2014). Prevention of leakage when incontinence was pronounced would have also reduced the partners' workload, in terms of laundry or protective measures (Ahnis \& Knoll, 2008). Furthermore, on days when partners were asked for help and rated patients' burden by incontinence as high, partners might have derived the well-documented benefits for support providers (e.g., Belcher et al., 2011; Kroemeke et al., 2019). Witnessing their partners' suffering is a stressor for caregivers (Monin \& Schulz, 2009, 2010). Being asked for assistance may not only increase the perception of being needed, but also of being able to effectively aid the partner and help control his suffering (for reviews, see Batson \& Powell, 2003; Monin \& Schulz, 2009, 2010).

In contrast to $\mathrm{H} 5$, no associations between patients' use of compensatory secondary control and partners' daily affect were observed. It was expected that patients' goal disengagement and protection of motivational resources would 
be associated with better overall affect not only in patients, but also in partners. This so soon following patients' RP, and based on prior qualitative findings (Phillips et al., 2000), we had assumed relief on the partners' side at patients' not exerting themselves and rather, perhaps temporarily, disengaging from goals. Moreover, we had expected that, although goal pursuit is often shared or coordinated in couples (Fitzsimons et al., 2015; Hoppmann \& Gerstorf, 2014) and goal disengagement by one partner may disrupt this balance, healthy partners would still benefit from the role of support providers (Kroemeke et al., 2019; Kuijer et al., 2001). Perhaps the opposing effects of relief and being needed, on the one hand, versus disruption of shared activities and partners' beginning emotional costs, on the other hand, were responsible for these null findings.

Exploratory analyses yielded no associations of patients' use of selective primary or secondary control strategies with partners' affect. On the one hand, patients' allocating more effort or intensifying commitment to goal pursuit might have gone unnoticed by partners. On the other hand, past findings indicated that partners feared patients might overtax themselves, in trying to keep up with their daily routines during early phases of rehabilitation, thus essentially practicing selective primary and likely also selective secondary control (Phillips et al., 2000). Future work might capture these effects by assessing partners' perceptions of patients' control strategies (as other reports) which should also yield a more proximal predictor of partners' affect.

\section{Limitations and Outlook}

In addition to this study's strengths, including a diary design and a relatively large sample of couples facing the sequelae of RP, also its limitations should be acknowledged. First, only same-time associations were reported, which leaves open the question of predictive direction and raises the issue of reverse causality for many of the findings reported above. In preliminary analyses not reported here, lagged models, using predictors from the day before to account for affect on the present day, were run but did not yield reliable findings. Possibly an experience sampling design with multiple assessments per day would have been more appropriate to capture shorter-term adaptations (Scholz, 2019). Further, low reliabilities in the measurement of change in control strategy indicators (specifically compensatory primary control) may have accounted for some of the encountered null findings. Whereas the use of more comprehensive and longer measures would have been desirable, one important goal was to keep participant load as low as possible. Additionally, medium to high interscale correlations likely compromised efficiency in statistical testing. However, sensitivity analyses where control strategies were entered in models without their competing counterparts indicated that the lack of efficiency was not too perilous. Finally, the population under study, that is, heterosexual couples adapting to men's sequelae of RP, confounded role and gender. Findings from this study might thus not generalize to other patient-caregiver populations where this confound is either not present or the other way around.

\section{Conclusion and Implications}

In conclusion, this study provided evidence on couples' daily affect at the onset of patients' functional limitations a few days after RP. Both patients' and partners' affect were directly associated with patients' incontinence on a given day, even while the respective other couple member's concurrent affect was controlled. Parts of these associations might be buffered by educating patients and their partners ahead of time not only about the nature and development of postsurgery incontinence, but also about how different technical aids may help alleviate its consequences (cf. Phillips et al., 2000; Resendes \& McCorkle, 2006). During this early phase of postsurgery rehabilitation, better affect in patients was tied to incontinence-specific control strategies that maximize self-reliant goal pursuit, especially when their symptom load was strong. This apparently beneficial misfit may indicate patients' desire to reclaim a presurgery level of functioning. At the same time, better affect in partners was evident when patients showed a closer fit between their control strategy use and symptom load. This constellation, if persistent, might give rise to conflict in couples in the long run. However, the overall development of most affect indicators in patients and partners suggested productive adaptation over the course of the week.

\section{Electronic Supplementary Material (ESM)}

The electronic supplementary material is available with the online version of this article at https://doi.org/ 10.1024/1662-9647/a000229

ESM 1. Tables. Table S1: Incontinence-specific Control Strategies: Items from the Diary Assessment; Table S2: Sensitivity Analyses, Reduced Models 1, 2, and 3: Patients' Affect - Associations with Incontinence and Daily Control Strategies; Table S3: Sensitivity Analyses, Reduced Models P1, P2 and P3: Partners' Affect - Associations with Partner-Reported Patient Burden by Incontinence and Daily Control Strategies. 


\section{References}

Ahnis, A., \& Knoll, N. (2008). Subjektives Belastungserleben bei alten Menschen mit Inkontinenz-Eine qualitative Analyse [Psychosocial burden of the elderly with incontinence-a qualitative analysis]. Zeitschrift für Gerontologie und Geriatrie, 41, 251-260. https://doi.org/10.1007/s00391-008-0559-2

Arrington, M. I. (2005). "She's right behind me all the way": An analysis of prostate cancer narratives and changes in family relationships. The Journal of Family Communication, 5, 141-162. https://doi.org/10.1207/s15327698jfc0502_5

Bandura, A. (1997). Self-efficacy: The exercise of control. New York, NY: Freeman.

Barlow, M. A., Wrosch, C., \& McGrath, J. J. (2019). Goal adjustment capacities and quality of life: A meta-analytic review. Journal of Personality, 88(2), 307-323. https://doi.org/10.1111/ jopy.12492

Barr, D. J., Levy, R., Scheepers, C., \& Tily, H. J. (2013). Random effects structure for confirmatory hypothesis testing: Keep it maximal. Journal of Memory \& Language, 68, 255-278. https:// doi.org/10.1016/j.jml.2012.11.001

Batson, C. D., \& Powell, A. A. (2003). Altruism and prosocial behavior. In T. Millon \& M. J. Lerner (Eds.), Handbook of psychology: Personality and social psychology (pp. 463-484). Hoboken, NJ: Wiley.

Belcher, A. J., Laurenceau, J.-P., Graber, E. C., Cohen, L. H., Dasch, K. B., \& Siegel, S. D. (2011). Daily support in couples coping with early stage breast cancer: Maintaining intimacy during adversity. Health Psychology, 30, 665-673. https://doi. org/10.1037/a0024705

Bolger, N., \& Laurenceau, J.-P. (2013). Intensive longitudinal methods: An introduction to diary and experience sampling research. New York, NY: Guilford Press.

Bray, F., Ferlay, J., Soerjomataram, I., Siegel, R. L., Torre, L. A., \& Jemal, A. (2018). Global cancer statistics 2018: GLOBOCAN estimates of incidence and mortality worldwide for 36 cancers in 185 countries. CA: A Cancer Journal for Clinicians, 68, 394-424. https://doi.org/10.3322/caac.21492

Carver, C. S., Scheier, M. F., \& Weintraub, J. K. (1989). Assessing coping strategies: A theoretically based approach. Journal of Personality and Social Psychology, 56, 267-283. https://doi. org/10.1037/0022-3514.56.2.267

Charlson, M. E., Szatrowski, T. P., Peterson, J., \& Gold, J. (1994). Validation of a combined comorbidity index. Journal of Clinical Epidemiology, 47, 1245-1251. https://doi.org/10.1016/08954356(94)90129-5

Chen, R. C., Basak, R., Meyer, A. M., Kuo, T. M., Carpenter, W. R., Agans, R. P., ... Godley, P. A. (2017). Association between choice of radical prostatectomy, external beam radiotherapy, brachytherapy, or active surveillance and patient-reported quality of life among men with localized prostate cancer. Journal of the American Medical Association, 317, 1141-1150. https://doi.org/10.1001/jama.2017.1652

Cranford, J. A., Shrout, P. E., lida, M., Rafaeli, E., Yip, T., \& Bolger, N. (2006). A procedure for evaluating sensitivity to within-person change: Can mood measures in diary studies detect change reliably? Personality and Social Psychology Bulletin, 32, 917-929. https://doi.org/10.1177/0146167206287721

Eton, D. T., Lepore, S. J., \& Helgeson, V. S. (2005). Psychological distress in spouses of men treated for early-stage prostate carcinoma. Cancer, 103(11), 2412-2418. https://doi.org/ 10.1002/cncr.21092

Fitzsimons, G. M., Finkel, E. J., \& vanDellen, M. R. (2015). Transactive goal dynamics. Psychological Review, 122, 648673. https://doi.org/10.1037/a0039654
Gray, R. E., Fitch, M., Phillips, C., Labreque, M., \& Fergus, K. (2000). Managing the impact of illness: The experiences of men with prostate cancer and their spouses. Journal of Health Psychology, 5, 531-548. https://doi.org/10.1177/135910530000500410

Hall, N. C., Chipperfield, J. G., Heckhausen, J., \& Perry, R. P. (2010). Control striving in older adults with serious health problems: A 9-year longitudinal study of survival, health, and well-being. Psychology and Aging, 25, 432-445. https://doi.org/ 10.1037/a0019278

Heckhausen, J., \& Schulz, R. (1995). A lifespan theory of control. Psychological Review, 102, 284-304. https://doi.org/10.1037/ 0033-295X.102.2.284

Heckhausen, J., Wrosch, C., \& Schulz, R. (2010). A motivational theory of lifespan development. Psychological Review, 117, 32 60. https://doi.org/10.1037/a0017668

Heckhausen, J., Wrosch, C., \& Schulz, R. (2013). A lines of defense model for managing health threats: A review. Gerontologist, 59, 438-447. https://doi.org/10.1159/000351269

Heckhausen, J., Wrosch, C., \& Schulz, R. (2019). Agency and motivation in adulthood and old age. Annual Review of Psychology, 70, 191-217. https://doi.org/10.1146/annurevpsych-010418-103043

Heidenreich, A., Bastian, P. J., Bellmunt, J., Bolla, M., Joniau, S. van der Kwast, T., ... Mottet, N. (2014). European Association of Urology. EAU guidelines on prostate cancer. Part 1: Screening, diagnosis, and local treatment with curative intent-update 2013. European Urology, 65, 124-137. https://doi.org/10.1016/ j.eururo.2013.09.046

Hoppmann, C. A., \& Gerstorf, D. (2014). Bio-behavioral pathways underlying spousal health dynamics: Their nature, correlates, and consequences. Gerontology, 60, 458-465. https://doi.org/ 10.1159/000357671

Karantanis, E., Fynes, M., Moore, K. H., \& Stanton, S. L. (2004). Comparison of the ICIQ-SF and 24-hour pad test with other measures for evaluating the severity of urodynamic stress incontinence. International Urogynecological Journal and Pelvic Floor Dysfunction, 15, 111-116. https://doi.org/10.1007/ s00192-004-1123-2

Knoll, N., Burkert, S., Roigas, J., \& Gralla, O. (2011). Changes in reciprocal support provision and need-based support from partners of patients undergoing radical prostatectomy. Social Science and Medicine, 73, 308-315. https://doi.org/10.1016/j. socscimed.2011.05.012

Knoll, N., Wiedemann, A. U., Schrader, M., Felber, J., Burkert, S. Daig, I., \& Heckhausen, J. (2015). Calibrating independence goals and partner support: Couples adjust to functional limitations after tumor surgery. Applied Psychology: Health and Well-Being, 7, 167-187. https://doi.org/10.1111/aphw.12043

Knoll, N., Wiedemann, A. U., Schultze, M., Schrader, M., \& Heckhausen, J. (2014). Prostate cancer patients gradually advance goals for rehabilitation after radical prostatectomy: Applying a lines-of-defense model to rehabilitation. Psychology and Aging, 29, 787-792. https://doi.org/10.1037/a0038311

Kroemeke, A., Knoll, N., \& Sobczyk-Kruszelnicka, M. (2019). Dyadic support and affect in patient-caregiver dyads following hematopoietic stem-cell transplantation: A diary study. Journal of Consulting and Clinical Psychology, 87(6), 541-550. https:// doi.org/10.1037/ccp0000398

Kuijer, R. G., Buunk, B. P., \& Ybema, J. F. (2001). Are equity concerns important in the intimate relationship when one partner of a couple has cancer? Social Psychology Quarterly, 64, 267-282. https://doi.org/10.2307/3090116

Mackinnon, A., Jorm, A. F., Christensen, H., Korten, A. E., Jacomb, P. A., \& Rodgers, B. (1999). A short form of the Positive and Negative Affect Schedule: Evaluation of factorial validity and invariance across demographic variables in a community 
sample. Personality and Individual Differences, 27, 405-416. https://doi.org/10.1016/S0191-8869(98)00251-7

Monin, J. K., \& Schulz, R. (2009). Interpersonal effects of suffering in older adult caregiving relationships. Psychology and Aging, 24, 681-695. https://doi.org/10.1037/a0016355

Monin, J. K., \& Schulz, R. (2010). The effects of suffering in chronically ill older adults on the health and well-being of family members involved in their care: The role of emotionrelated processes. GeroPsych, 23, 207-213. https://doi.org/ 10.1024/1662-9647/a000024

Phillips, C., Gray, R. E, Fitch, M. I., Labrecque, M., Fergus, K., \& Klotz, L. (2000). Early postsurgery experience of prostate cancer patients and spouses. Cancer Practice, 8, 165-171. https://doi.org/10.1046/j.1523-5394.2000.84009.x

Prabhu, V., Sivarajan, G., Taksler, G. B, Laze, J., \& Lepor, H. (2014). Long-term continence outcomes in men undergoing radical prostatectomy for clinically localized prostate cancer. European Urology, 65, 52-57. https://doi.org/jeururo.201308.006

Preacher, K. J., Curran, P. J., \& Bauer, D. J. (2006). Computational tools for probing interaction effects in multiple linear regression, multilevel modeling, and latent curve analysis. Journal of Educational and Behavioral Statistics, 31, 437-448. https://doi. org/10.3102/10769986031004437

Resendes, LA., \& McCorkle, R. (2006). Spousal responses to prostate cancer: An integrative review. Cancer Investigation, 24, 192-198. https://doi.org/10.1080/07357900500524652

Rondorf-Klym, L. M., \& Colling, J. (2003). Quality of life after radical prostatectomy. Oncology Nursing Forum, 30(2), 24-32. https://doi.org/10.1188/03.0NF.E24-E32

Rothbaum, F., Weisz, J. R., \& Snyder, S. S. (1982). Changing the world and changing the self: A two process model of perceived control. Journal of Personality and Social Psychology, 42, 5-37. https://doi.org/10.1037/0022-3514.42.1.5

Schilling, O., Wahl, H.-W., Boerner, K., Horowitz, A., Reinhardt, J. P., Cimarolli, V. R., ... Heckhausen, J. (2016). Developmental regulation with progressive vision loss: Use of control strategies and affective well-being. Developmental Psychology, 52, 679-694. https://doi.org/10.1037/dev0000099

Scholz, U. (2019). It's time to think about time in health psychology. Applied Psychology: Health and Well-Being, 11(2), 173-186. https://doi.org/10.1111/aphw.12156

Schulz, R., \& Heckhausen, J. (1998). Health-specific optimization in primary and secondary control scales. Pittsburgh, PA: University of Pittsburgh Press.

Schulz, R., Heckhausen, J., \& O'Brien, A. (2000). Negative affect and the disablement process in late life. A lifespan control theory approach. In S. B. Manuck, R. Jennings, B. S. Rabin, \& A. Baum (Eds.), Behavior, health, and aging (pp. 119-133). Mahwah, $\mathrm{NJ}$ : Erlbaum.
Shrout, P. E., Stadler, G., Lane, S. P., McClure, M. J., Jackson, G. L., Clavel, F. D., ... Bolger, N. (2018). Initial elevation bias in subjective reports. Proceedings of the National Academy of Sciences, 115(1), e15-e23. https://doi.org/10.1073/pnas. 1712277115

Wahl, H.-W., Becker, S., Burnmedi, D., \& Schilling, O. (2004). The role of primary and secondary control in adaptation to agerelated vision loss: A study of older adults with macular degeneration. Psychology and Aging, 19, 235-239. https://doi. org/10.1037/0882-7974.19.1.235

Wallis, C. J. D., Saskin, R., Choo, R., Herschorn, S., Kodama, R. T., Satkunasivam, R., ... Nam, R. K. (2016). Surgery versus radiotherapy for clinically localized prostate cancer: A systematic review and meta-analysis. European Urology, 70, 21-30. https://doi.org/10.1016/j.eururo.2015.11.010

Wrosch, C., Schulz, R., \& Heckhausen, J. (2004). Health stresses and depressive symptomatology in the elderly: A control-process approachCurrent Directions in Psychological Science, 13, 17-20. https://doi.org/10.1111/j.0963-7214.2004.01301005.x

\section{History}

Received July 23, 2019

Accepted February 26, 2020

Published online May 29, 2020

\section{Conflict of Interest}

The authors declare no conflict of interest.

\section{Funding}

This research was supported by a grant from the Deutsche Forschungsgemeinschaft (DFG; KN 937/3-1). The contribution of Aleksandra Luszczynska was supported by grant no. BST/WROC/ 2018/A/09 from the Ministry of Science and Higher Education, Poland.

\section{ORCID}

Nina Knoll

(iD) https://orcid.org/0000-0002-0871-5559

\section{Nina Knoll}

Division Health Psychology

Department of Education and Psychology

Freie Universität Berlin

Habelschwerdter Allee 45

14195 Berlin

Germany

nina.knoll@fu-berlin.de 